\title{
CNS involvement in malignant atrophic papulosis (Kohlmeier-Degos disease): vasculopathy and coagulopathy
}

\author{
DARAB K DASTUR, * B S SINGHAL, $\dagger$ AND H J SHROFF \\ From the Neuropathology Unit,* the Department of Neurology, $\dagger$ and the Department of \\ Dermatology, $\ddagger$ Grant Medical College and J J Group of Hospitals, Bombay
}

S UMMARY The clinical features in a 42 year old man with malignant atrophic papulosis with CNS involvement are described. They included mental dysfunction, paraesthesiae, weakness of left limbs, with pyramidal tract signs, bilateral ptosis, progressing to total ophthalmoplegia and obtundation. There were two crops of characteristic papular lesions on trunk and limbs, with terminal evidence of a coagulopathy and bruises, resulting in death in six months. Papular biopsy revealed multiple microinfarcts in the dermal collagen. The brain showed multiple small haemorrhagic infarcts of both hemispheres, the lower mid-brain, pons and a cerebellar peduncle. Microscopy showed fibrin exudation in the leptomeninges, various stages of thrombosis of small arteries without inflammatory reaction, and corresponding acute and subacute microinfarcts. The pathogenetic basis of the disease appeared to be a combined vasculopathy and coagulopathy.

Kohlmeier ${ }^{1}$ and Degos et $a l^{2}$ almost simultaneously described a rare and potentially fatal papulosis of the skin, with occlusive changes in the small arteries as the basic lesion. Subsequently Degos $e t$ al $^{3}$ described the condition as the "syndrome cutaneo-intestinal mortel," because the majority of patients died of multiple infarcts of the small intestine. Over the course of the past three decades about 100 cases have been described from different parts of the world.

Of greater interest are the unusual cases where the characteristic malignant atrophic papulosis of the skin is accompanied by widespread occlusive vasculopathy of the brain and spinal cord with consequent multiple infarcts. The first to describe such a combined disorder were Nomland and Layton $^{5}$ who also reported vascular lesions in the heart and kidney. The subsequent cases were those of Gever et al $l^{6}$ and Culicchia et al $^{7}$ (the same case), Winkleman et $a^{8}$ (two cases with detailed neuropathology), Strole et $a l^{4}$ (a patient with

Address for reprint tequests: Dr DK Dastur, Neuropathology Unit, Sir JJ Group of Hospitals, Bombay-8, India.

Accepted 25 September 1980 associated malabsorption and renal lesions), Vanderhaegen et $a l^{9}$ (with many motor cranial nerves involved). Hall-Smith ${ }^{10}$ (describing a diseasein a mother and son, Horner, ${ }^{11}$ and McFarland $e t a^{12}$ (with perivascular infiltrates similar to those seen in other viral encephalopathies). To this may be added a tenth case by Basset et al. ${ }^{13}$ A comprehensive account of the cutaneous symptoms, the intestinal disorder, the neuro-occular manifestations, the basic pathology and pathogenetic considerations, has been presented by Degos and Kalis. ${ }^{14}$ Generally when the CNS lesions are present the intestinal lesions are absent or mild.

We report here probably the eleventh recorded neuropathologically studied case of KohlmierDegos disease, stressing the possible combined pathogenetic mechanisms of coagulopathy and vasculopathy.

\section{Case report}

Clinical features SBR, a man aged 42 years, a postal clerk, was first seen on 22 July 1970. In 
January 1970, he had noted a few papules over the body. In March 1970 he became forgetful. On 8 July 1970, he complained of left sided paraesthesiae and developed an acute left hemiparesis. In 1958, he had been treated for pulmonary tuberculosis.

Examination on admission showed papules with central umblication over the upper extremities, chest and abdomen (fig 1A). Neurological examination showed impairment of memory for recent events, mild blurring of disc margins, dysarthria, left hemiparesis with extensor left plantar and impairment of pain sensibility on left side. Examination was otherwise normal. Blood pressure was $146 / 90 \mathrm{mmHg}$. He continued to deteriorate. He devloped retention of urine and by August he had bilateral pyramidal signs with brisk tendon jerks and bilateral extensor plantar responses. Later he showed signs suggesting brain stem involvement: nystagmus on looking to the right, bilateral ptosis (left more than right), the left pupil became larger than the right and

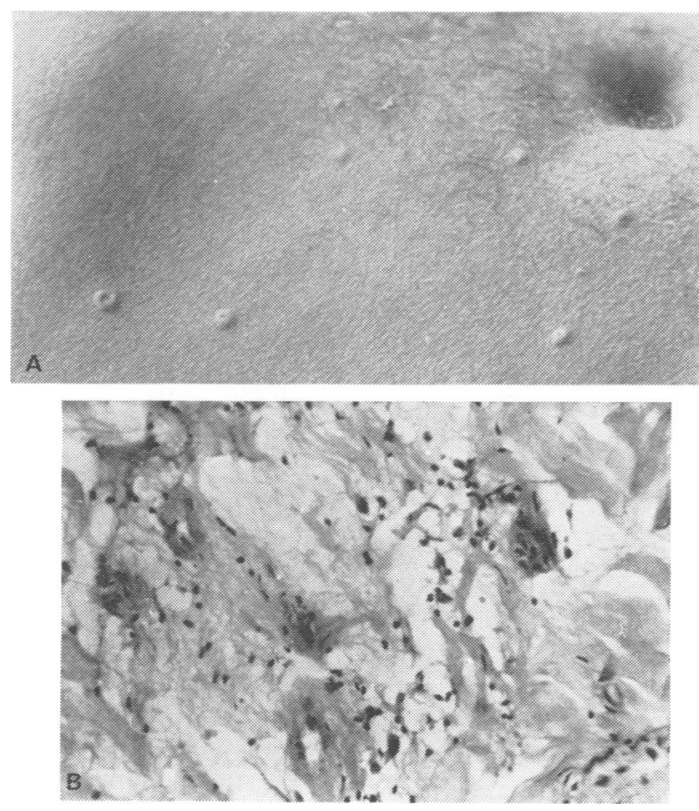

Fig 1 (A) Abdominal skin of the patient (umbilicus at top right) showing papules, one of which (at lower left) is umbilicated. (B) One of the several small infarcts in the skin showing pale area of broken down collagen (surrounded by better preserved collagen bundles), including five small blood vessels, some thickened, and a few scattered small mononuclear cells. (B) Haematoxylin and eosin $\times 175$. reacted sluggishly to light. On 26 August, he had hiccups and became semiconscious. The doll's eye manoeuvre only elicited abduction of the right eye. On 5 September, he only responded to pain by extending the limbs. Three days before his death on 12 September 1970, he had bleeding and ulceration of left pinna, bruises and haematomas over the pressure sites of the scalp and back. There were no abdominal signs at any stage.

The clinical picture in this patient with skin lesions and neurological involvement suggested Kohlmeier-Degos Disease.

Clinical pathology The blood leucocyte (total WBC) count was $9.6 \times 10^{9} / 1$, with neutrophil polymorphs $62 \%$, eosinophils $8 \%$, lymphocytes $24 \%$ and monocytes $6 \%$. The erythrocyte sedimentation rate was $20 \mathrm{~mm}$ at the end of one hour (Westergren method). The urine was normal. Fasting blood sugar level was 4.99 and post-prandial $5.38 \mathrm{mmol} / 1$. The VDRL was negative. Serum protein concentration was $68 \mathrm{~g} / 1$, with albumin $29.6 \mathrm{~g} / 1$, alpha 1 globulin $2 \cdot 2 \mathrm{~g} / 1$, alpha 2 globulin $11.2 \mathrm{~g} / 1$, beta globulin $10.4 \mathrm{~g} / 1$ and gamma globulin $14.6 \mathrm{~g} / 1$. Serum alkaline phosphatase was 0.5 King-Armstrong Units, glutamate-oxaloacetate transaminase $0.65 \mathrm{~g} / 1$ and glutamate-pyruvate transaminase $0.70 \mathrm{~g} / 1$. The ECG was normal. EEG showed abnormalities on the right side. Chest and skull radiographs showed no abnormality. Right carotid angiogram and an air encephalogram were normal. Routine examination of cerebro-spinal fluid (CSF) on three occasions showed marked elevation of protein (between 1.60 and $2 \cdot 16 \mathrm{~g} / \mathrm{l})$ and of cells up to $1 \times 10^{6} / 1$ (lymphocytes only). Lange's Colloidal Gold Curve was normal (all zeros).

The blood erythropoietic and coagulation factors on two occasions are shown in the table.

Pathology The main gross neuropathological findings were localised thrombosis of the superior sagittal sinus, the presence of multiple small surface and subsurface haemorrhagic infarcts of both cerebral hemispheres, right more than left, haemorrhagic softening of the lower mid-brain and pons and haemorrhage in a cerebellar peduncle. Microscopic examination showed all possible stages of thrombosis of the arteries with extensive intravascular and extravascular deposition of fibrin in the superolateral and sulcal meninges, accompanied by corresponding stages of infarction, mainly in the cerebral cortex; and thrombosis of some of the parenchymal vessels of the brain stem associated with acute softening and microhaemorrhages. The changes in the other organs included small areas of pallor and disappearance of collagen in one of the skin papules, with a mild mononuclear cell reaction representing micro-infarction, small haemorrhages in the stomach and kidney and severe acutesubacute inflammatory reaction in lungs and bladder. The essential pathological features are illustrated in figs $1 \mathrm{~B}, 2 \mathrm{~A}$ and $\mathrm{B}, 3 \mathrm{~A}, \mathrm{~B}$, and $\mathrm{C}$, and brief descriptions are given in the legends. 

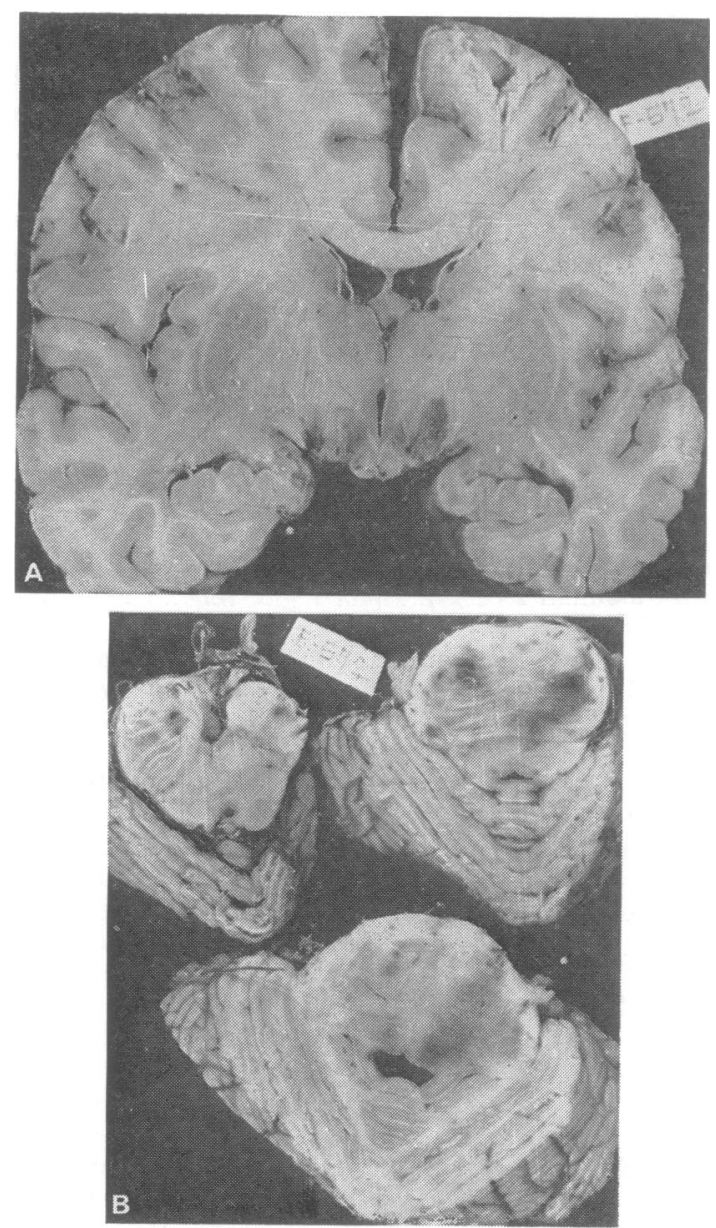

Fig 2 (A) Coronal slice through cerebral hemispheres at the level of the posterior part of frontal lobes and anterior part of temporal lobes showing small haemorrhagic areas in the superolateral gyri, the right insular cortex, in both sub-thalamic and sub-pallidal regions and in the medial tips of the temporal lobes. The right hemisphere is appreciably smaller than the left. (B) Sections through three levels of the pons, the one at the upper left being through the ponto-mesencephalic junction, showing haemorrhage on both sides, with the larger one on the right extending into the middle cerebellar peduncle (lower slice).
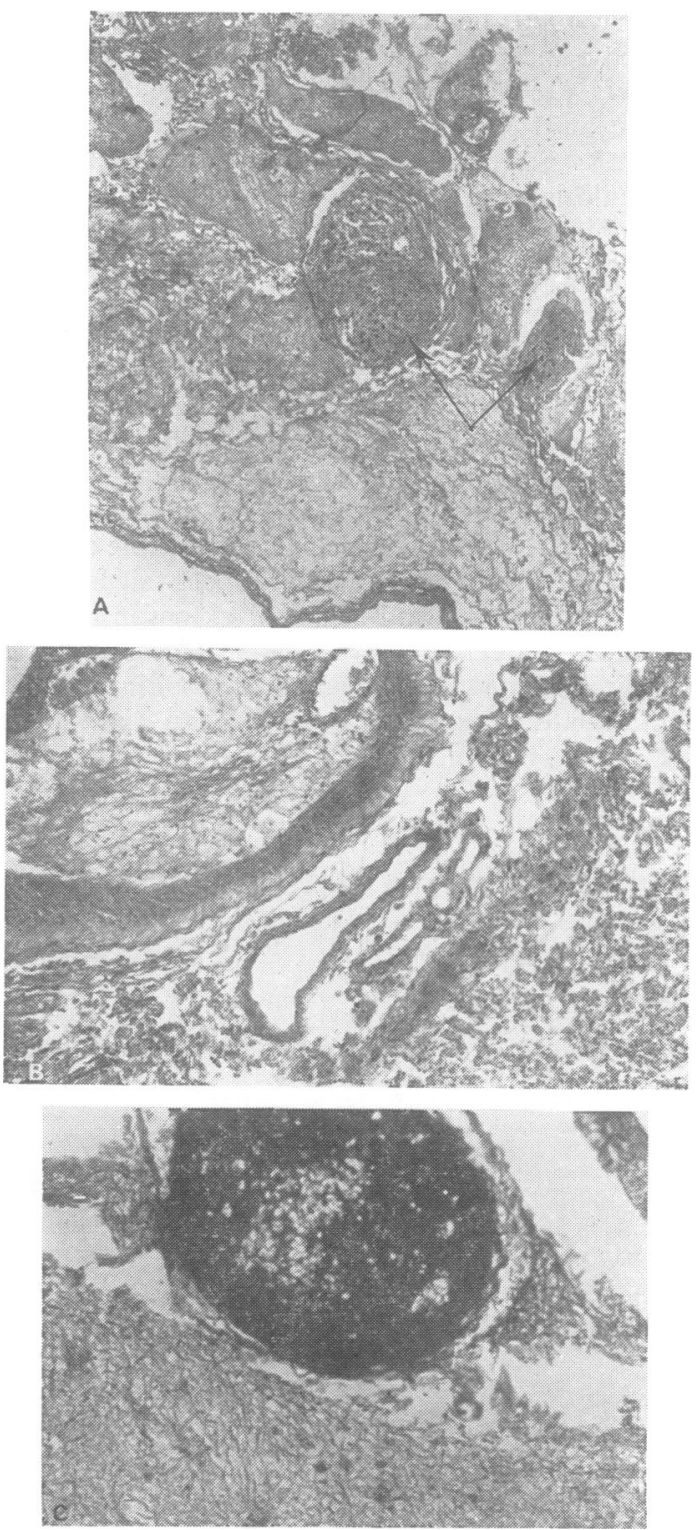

Fig 3 (A) Thickened frontal leptomeninges showing two thrombosed vessels (split arrow) (diameter of larger vessel $=125 \mu \mathrm{m}$ ), and pale or dark masses of fibrin. (B) Parietal leptomeninges showing early fibrin-thrombus in artery (diameter $=630 \mu \mathrm{m}$ ) at top left, normal patent vein in the middle, and infarcted cortex at lower right. (C) Dense fibrin thrombus totally blocking small meningeal artery (diameter $=205 \mu \mathrm{m})$; mild astrocytic reaction in cortical surface. $(A) H \& E$ $\times 32$; (B) $H \& E \times 63$; (C) PTAH $\times 160$. 
Table Erythropoietic and coagulation factors

\begin{tabular}{|c|c|c|}
\hline Blood sample of & 17 August 1970 & 10 September 1970 \\
\hline $\begin{array}{l}\text { Haemoglobin } \\
\text { RBC (PCV) } \\
\text { Platelets } \\
\text { Plasma prothrombin time } \\
\text { Serum prothrombin time } \\
\text { Activated PTT* } \\
\text { Bleeding and clotting times } \\
\text { Clot retraction }\end{array}$ & $\begin{array}{l}15 \cdot 5 \mathrm{~g} / \mathrm{dl} \\
5.0 \times 10^{12} / 1(0 \cdot 45) \\
125 \times 10^{\circ} / 1 \\
\text { Pt } 13 \mathrm{~min}, \text { control } 12 \mathrm{~min} \\
\mathrm{Pt} 39 \mathrm{~min}, \text { control } 42 \mathrm{~min} \\
-147 \mathrm{~s} \text { and } 310 \mathrm{~s} \\
20 \% \text { of serum (good) }\end{array}$ & $\begin{array}{l}10 \cdot 5 \mathrm{~g} / \mathrm{dl} \\
4.0 \times 10^{12} / 1(0.37) \\
93 \times 10^{9} / 1 \\
\text { Pt } 21 \mathrm{~min} \text {. control } 12 \mathrm{~min} \\
\mathrm{Pt} 40 \mathrm{~min} \text {, control } 41 \mathrm{~min} \\
\mathrm{Pt} 48 \mathrm{~min}, \text { control } 34 \mathrm{~min} \\
=\end{array}$ \\
\hline
\end{tabular}

*PTT = Partial thromboplastin time

$\mathrm{Pt}=$ Patient

\section{Discussion}

McFarland et al ${ }^{12}$ reviewed the main clinicopathological features of nine cases of this disease with neurological involvement. They ranged in age from three months to 55 years, seven being between the ages of 16 and 47 years, with a duration of symptoms of one to six years. Hemiparesis or hemiplegia, focal seizures, facial paresis, incoordination, dysarthria and hiccups, were the more common CNS signs; with multiple cerebral infarcts, with or without haemorrhagic changes and similar changes in the cerebellum or spinal cord, constituting the neuropathological findings. There was fair clinicopathological correlation at different stages of the neurological manifestation in our patient. Thus, for instance, the left limbs were more severely affected than the right, and the infarcts in the right cerebral hemisphere were more prominent than those in the left, and the right frontal lobe was smaller. The occular and brain stem signs were readily explained by the gross and microscopic, haemorrhagic and ischaemic lesions in the pons.

The mechanism of production of the vascular lesions which produced the small multiple infarcts of the brain, and which was responsible for the death of the patient, merits discussion. The primary pathogenetic mechanism that we considered in our patient was some kind of infection, or an immunological reaction to infection, or both. With no inflammatory cells in or around any of the several blood vessels encountered in the leptomeninges and CNS parenchyma, an infective aetiology was hard to support. Of the 10 published cases only that of Howard and Nishida ${ }^{15}$ appears to have had viral aetiology, as suggested from the presence of virion-like particles on electronmicroscopy, in the degenerating endothelial cells of the cutaneous blood vessels. In only two other cases, those of McFarland et al ${ }^{12}$ and Gever et al, ${ }^{6}$ was there a preceding infection with herpes zoster virus and the presence in the brain of vasculitis and peri-vasculitis with small mononuclear cells. As this viral infection was a year or more prior to the onset of papulosis, the terminal vasculopathy was believed to be an immunological reaction. Degos and Kalis ${ }^{14}$ suggest that their own discovery of antiarterial antibodies provided evidence of an autoimmune mechanism.

It is of interest that atrophic lesions closely resembling malignant atrophic papulosis were observed in SLE by Black and Hudson. ${ }^{16}$ It is generally conceded, ${ }^{4} 81214$ however, that the vasculopathy in malignant atrophic papulosis is different from that in SLE, where both arteries and veins are involved and the kidney is the site of predilection; from that in peri-arteritis nodosa, where it is more widespread and has florid inflammatory reaction; and from that in thromboangiitis obliterans where again inflammation is prominent, skin lesions do not occer and terminal parts of extremities are involved preferentially. One other rare form of vasculopathy, namely Eales' disease with CNS involvement, ${ }^{17} 18$ differs from malignant atrophic papulosis in being a more proliferative disorder, with veins involved preferentially, but with a frequent background of tuberculosis which our patient had also had in the past.

Gajdusek et al ${ }^{19}$ published a provocative report, wherein a neurosurgeon with clear cutaneous manifestations of Kohlmeier-Degos disease died of the typical neurological and neuropathological manifestations of Jacob-Creutzfeldt's disease. An injection of his brain extract produced the latter disease in a chimpanzee and a squirrel monkey. Gajdusek et al suggested that the aetiologic agent of these two disorders might be the same virus, or that malignant atrophic papulosis activated a pre-existing Jacob-Creutzfeldt's infection.

As the neuropathological process in our patient was characterised by the virtual absence of any inflammatory reaction, and as there was extensive presence of fibrin thrombi and fibrinous exuda- 
tion, a disorder in clotting mechanism was considered. Roegnik and Farmer ${ }^{20}$ found increased increased serum fibrinogen levels in two of their three patients, and suggested that fibrinogen is converted to a "cryo-profibrin" in the presence of thrombin at cold temperatures. They also reported increased fibrinogen levels in patients with systemic lupus erythematous (SLE) with renal lesions. Increased fibrinogen levels might be a nonspecific finding initiated by the clotting mechanism itself, and arterial thrombosis can be accompanied by increased, decreased or normal fibrinogen levels. It appeared that we were dealing with a "consumptive coagulopathy" in our patient, as, evidenced by (1) a fall in the platelet count in the second blood sample (collected two days before death), (2) an increase in plasma prothrobin time, (3) a rise in the activated partial thromboplastin time, and (4) a fall in circulating haemoglobin level and packed-cell volume in the second sample. The stimulus for the terminal abnormal clotting in and around the blood vessels of the brain might have been some change in the vessel wall of an inflammatory or immunological nature, or the presence of infection elsewhere in the body. In our patient there was postmortem evidence for the latter, in the form of severe subacute pneumonitis and cystitis.

We are indebted to the Department of Haematology of the JJ Hospitals for the blood reports of 1970; and to Dr Asha Veer, haematologist of Bombay Hospital, for her comments. Thanks are due to Ms N Patkar and Mr V Darekar, for the histopathologic preparations, to Mr N Solanki for the dark room work and to Ms Emma Alvares for the typing.

\section{References}

1 Kohlmeier W. Multiple Hautnekrosen bei thrombangiitis obliterans. Arch Klin Exp Dermatol 1941; 181:783-92.

2 Degos R, Delort J, Tricot R. Dermatitie papulosquameuse atrophiante. Quoted by Degos and Kalis. ${ }^{14}$

3 Degos R, Delort J, Tricot R. Papulose atrophiante maligne (syndrome cutaneo-intestinal mortel). Quoted by Degos and Kalis. ${ }^{14}$

4 Strole WE, Clark WH, Isselbacher KJ. Progressive arterial occlusive disease (KohlmeierDegos). A frequent fatal cutaneosystemic disorder. New Engl J Med 1967; 276:195-201.

5 Nomland R, Layton JM. Malignant papulosis with atrophy (Degos): Fatal cutaneo-intestinal syndrome. Arch Dermatol 1960; 81:181-8.

6 Gever SG, Freeman RG, Knox JM. Degos' disease (Papulosis Atrophicans Maligna): Report of a case with degenerative disease of the central nervous system. South Med J 1962; 55:56-60.

7 Culicchia CF, Gol A, Erickson EE. Diffuse central nervous system involvement in papulosis atrophicans maligna. Neurol (Minneap) 1962; 12:503-9.

8 Winkelmann RK, Howard FM, Perry HO, Miller RH. Malignant papulosis of skin and cerebrum: A syndrome of vascular thrombosis. Arch Dermatol 1963; 87:94-102.

9 Vanderhaeghen JJ, Joffroy A, Achten G, Warszanski M, Reynaers $H$. Lesions vasculaires dans la papulose atrophiante maligne de Degos. Quoted by Degos and Kalis. ${ }^{14}$

10 Hall-Smith P. Malignant atrophic papulosis (Degos' disease): Two cases occurring in the same family. $\mathrm{Br} J$ Dermatol 1969; 81:817-22.

11 Horner FA, Myers GJ, Stumpf DA, et al. Malignant atrophic papulosis (Kohlmeier-Degos' disease) in childhood. Neurol (Minneap) 1976; 26:317-21.

12 McFarland HR, Wood WG, Drowns BV, Meneses ACO. Papulosis atrophicans maligna (KohlmeierDegos disease): A disseminated occlusive vasculopathy. Ann Neurol 1978; 3:388-92.

13 Besset A, Kurtz D, Bergoend H, Grosshans E, Maleville J, Rohmer Fr. Papulose atrophiante maligne de Degos avec atteinte du systeme nerveux central et presence d'anticorps anti-artere. Quoted by Degos and Kalis. ${ }^{14}$

14 Degos R, Kalis B. La papulose atrophiante maligne. La Revue du Praticien 1969; 19:4335-41.

15 Howard RO, Nishida S. A case of Degos' disease with electron microscopic findings. Trans $\mathrm{Am}$ Acad Ophthalmol Otolaryngol 1969; 73:1097-112.

16 Black MM, Hudson PM. Atrophic blanche lesions (Degos' disease) in systemic lupus erythematosus. Br J Dermatol 1976; 95:649-52.

17 Singhal BS, Dastur DK. Eales' disease with neurological involvement. 1-Clinical features in 9 patients. J Neurol Sci 1976; 27:313-21.

18 Dastur, DK, Singhal BS. Eales' disease with neurological involvement. 2. Pathology and Pathegenesis. J Neurol Sci 1976; 27:323-45.

19 Gajdusek DC, Gibbs CJ, Earle K, Dammin GJ, Schoene WC, Tyler HR. Transmission of subacute spongiform encephalopathy to the chimpanzee and squirrel monkey from a patient with papulosis atrophicans maligna of KohlmeierDegos. Proc $X$ Int Congress of Neurology. A Subirana, JM Burrows (eds). Amsterdam: Excerpta Medica, 1977; 290-2.

20 Roenigk HH, Farmer RG. Degos' disease (malignant papulosis). JAMA 1968; 206:1508-14. 